\title{
The behaviour of some hyacinth varieties in forced culture
}

\author{
Zsolt SZÉKELY-VARGA, Timea HITTER (BURU), \\ Alex-Peter COTOZ, Roxana Alexandra SABO, Maria CANTOR* \\ Department of Horticulture and Landscaping, Faculty of Horticulture, \\ University of Agricultural Sciences and Veterinary Medicine, Cluj-Napoca \\ e-mail: szekelyvarga.zsolt@gmail.com, hittertimea@yahoo.com, alex.p.cotoz@gmail.com, \\ *Corresponding author: marcantor@yahoo.com
}

Manuscript received August 23, 2019; revised September 30, 2019; Accepted October 10, 2019

\begin{abstract}
This paper presents the behaviour of five hyacinth varieties: 'City of Haarlem', 'Blue Jacket', 'Miss Saigon', 'Jan Boss', and 'Double Prince of Love' in forced culture under the influence of different culture substrates. For this purpose, the following parameters were monitored concerning the main characteristics: number of flowers from inflorescence, length of stem flower, earliness of flowering period, and the flowers' blooming period. The results of this work show that in culture substrate garden soil and sand $(1: 1)$ the best results were obtained regarding the length of the floral stem, number of flowers from inflorescence, and flowering period, and less favourable results were obtained for bloom precocity.
\end{abstract}

Keywords: flowering, morphological characteristics, potted plants, substrate

\section{Introduction}

Hyacinths are popular garden flowers, but they can also be found in markets, flower shops, as cut flowers, or in pots.

The genus Hyacinthus brings together approximately 30 bulbous rustic species [1]. The current Dutch cultivars have been imported in the middle of the $16^{\text {th }}$ century, and they are descended from a blue species of Hyacinthus orientalis [2].

In the recent years, the floricultural greenhouse industry produced potted plants and cut flowers in Romania from a variety of bulbous species such as tulips, daffodils, Dutch iris, or lilies. According to Janse [3], in the early $18^{\text {th }}$ century, the forcing of hyacinth bulbs was already known. 
At the beginning of this century, temperature treatments were introduced for hyacinths plants to produce high-quality flower and sufficient stem length [4].

According to Selaru [5], the thermal treatments to which the bulbs are subjected during storage aim at forming and preserving the floral bud until the bulb is planted. For example, bulbs intended for flowering in December-January are harvested in the first part of June and kept for two weeks at $30{ }^{\circ} \mathrm{C}$, after which the temperature is lowered to $25.5^{\circ} \mathrm{C}$ for three weeks, and then it is maintained at $23{ }^{\circ} \mathrm{C}$ until the flower is fully formed. Following this phase, storage is kept at $17{ }^{\circ} \mathrm{C}$ until the bulbs are planted, which takes place in September (Table 1).

Table 1. Calendar of forcing hyacinths with thermally treated bulbs

\begin{tabular}{cccc}
\hline $\begin{array}{c}\text { Planting } \\
\text { period }\end{array}$ & $\begin{array}{c}\text { Flowering } \\
\text { periods }\end{array}$ & $\begin{array}{c}\text { Temperature in } \\
\text { rooting room }\end{array}$ & $\begin{array}{c}\text { Preservation } \\
\text { temperature in the } \\
\text { month before planting }\end{array}$ \\
\hline 15-30 Sept. & $20-25 \mathrm{Dec}$. & $9^{\circ} \mathrm{C}$ & $13^{\circ} \mathrm{C}$ \\
1 10 Oct. & $25-15 \mathrm{Jan}$. & $9^{\circ} \mathrm{C}$ & $17^{\circ} \mathrm{C}$ \\
15 Oct. & $15 \mathrm{Jan} .-15 \mathrm{Feb}$. & $9^{\circ} \mathrm{C}$ & $17^{\circ} \mathrm{C}$ \\
15 Nov. & $15 \mathrm{Feb}-15 \mathrm{Mar}$. & $9^{\circ} \mathrm{C}$ & $17^{\circ} \mathrm{C}$ \\
\hline 15 Dec. & $15 \mathrm{Mar}-15 \mathrm{Apr}$. & $9^{\circ} \mathrm{C}$ & $17^{\circ} \mathrm{C}$ \\
\hline & & & Source: $[5]$
\end{tabular}

Planting bulbs for forced cultivation is done in pots with a diameter of 9-11 $\mathrm{cm}$ or on rails, in a light, well-drained substrate. The planting distances are very small, 2-3 cm, ensuring a density of 300-350 plants per square meter. The depth of planting should be such that the leaf cone remains at the surface of the substrate [1]. Bulb size for culture in pots should be more than $16 \mathrm{~cm}$ in circumference [6]. Immediately after planting, bulbs need 8-12 weeks of low temperature, 4$5{ }^{\circ} \mathrm{C}$, according to [1], or $9^{\circ} \mathrm{C}$ for a good rooting [5].

The need for low temperature duration varies depending on the variety and the finished product at recovery. In the case of cut flowers, the period of cold is longer in order to obtain longer flowering rods. For two weeks from planting, a maximum temperature of $13{ }^{\circ} \mathrm{C}$ can be permitted because it would otherwise damage the normal growth of the plant. Towards the end of the rooting period, the temperature may drop to $7{ }^{\circ} \mathrm{C}$.

In the case of untreated bulbs, the temperature must be between 5 and $9{ }^{\circ} \mathrm{C}$.

In the case of late forces, shoots grow too much in the rooting room (this must exceed $8-10 \mathrm{~cm}$ ). In this situation, as soon as the bulbs have rooted at $9{ }^{\circ} \mathrm{C}$, the temperature must be lowered to $2-0^{\circ} \mathrm{C}$. These plants will no longer need dark conditions for the elongation of the stem [5, 7].

After the bulbs rooted and benefited from the necessary cold, the pots are transferred to the greenhouse where the forcing itself occurs by increasing the 
temperature gradually to the level of $22-23{ }^{\circ} \mathrm{C}$. This thermal threshold is maintained until the buds begin to colour when temperature drops to $20{ }^{\circ} \mathrm{C}$, and when they are all coloured, it decreases and remains at $15^{\circ} \mathrm{C}$ until it is recovered $[1,5]$.

Regarding the light within the first 6-7 days from the beginning of the forcing itself, the plants intended for use as cut flowers will be covered with a black foil for the elongation of the floral stem, after which light is ensured at the minimum intensity of 10,000 lux [8].

Hyacinths may also be forced to flourish earlier in their cultivation in greenhouses [9]. Planting bulbs is done by the end of October under natural environmental conditions. In January-February, the plastic material is installed using heating as well if necessary - for the plants to benefit from the warmth needed for early flowering.

Considering the importance of this bulb flower crop, studies were focused on the behaviour of some Hyacinthus orientalis L. varieties in forced culture. Based on the observations and the measurements carried out for the morphological characteristics, the best varieties can be promoted on Romanian market as pot plants.

\section{Materials and methods}

The forcing of hyacinth bulbs was accomplished in the didactical greenhouses of the University of Agricultural Sciences and Veterinary Medicine, Cluj-Napoca (UASMV), during the period of 15 November 2017-30 March 2018.

The experiment consists in analysing the influence of culture substrate on the main morphological characteristics of the flower of some hyacinth varieties. The biological materials used to achieve this research were five of the most cultivated cultivars of Hyacinthus orientalis: 'City of Haarlem' (Fig. 1), 'Blue Jacket' (Fig. 2), 'Miss Saigon' (Fig. 3), 'Jan Bos' (Fig. 4), and 'Double Prince of Love' (Fig. 5). The cultivars are planted on pots in three culture substrates: garden soil, garden soil + peat $(1: 1)$, and garden soil + sand (1:1).

The combination of the two experimental factors with three and five graduations resulted 15 experimental variants. In the experiments, a completely randomized design and 3 replications were used. Five bulbs were used for each variant/replication with a total of 15 plants per variant.

Throughout the storage and until planting, the hyacinth bulbs were kept in a dry storage place at a temperature of $18{ }^{\circ} \mathrm{C}$.

In the rooting chamber, the bulbs in the pots were kept at a temperature of $5-9{ }^{\circ} \mathrm{C}$, and during the forced period in the heated greenhouse the temperature 
was kept in the range of $21-25{ }^{\circ} \mathrm{C}$ during the day and between 15 and $16{ }^{\circ} \mathrm{C}$ at night.

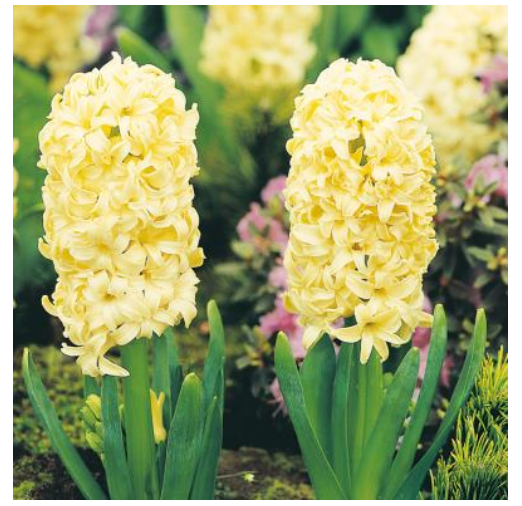

Figure 1. 'City of Haarlem' [10]

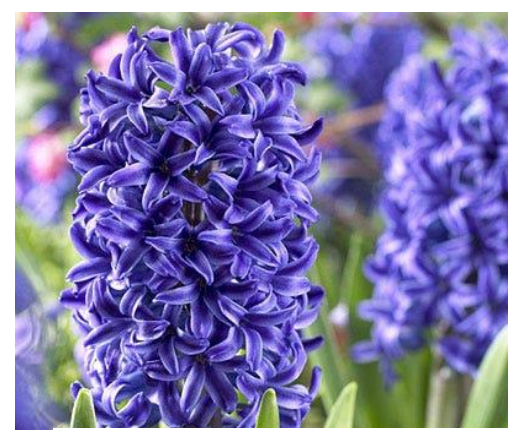

Figure 2. 'Blue Jacket' [11]

The experiment consists in analysing the influence of culture substrate on

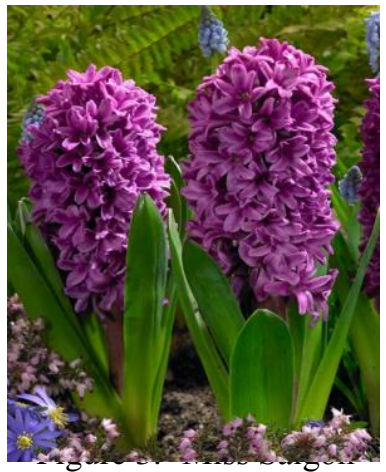

[12]

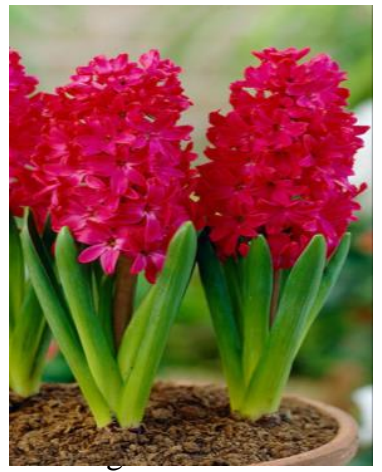

[13]

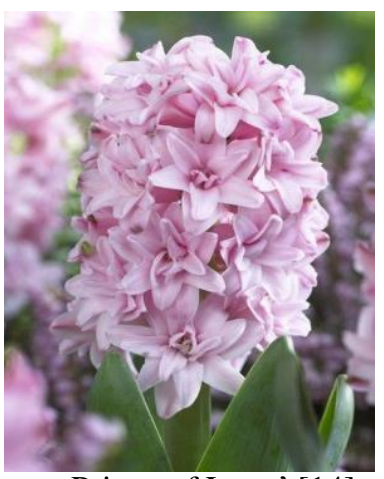

Prince of Love' [14]

the main morphological characteristics of the flower of some hyacinth varieties (length of stem flower, number of flower/inflorescences, precocity of flowering, and flowering period).

The data were statistically analysed using analysis of variance test [15]. 


\section{Results and discussions}

Figure 6 shows the average data recorded for the average height of floral stems in the five studied varieties under the influence of the culture substrate.

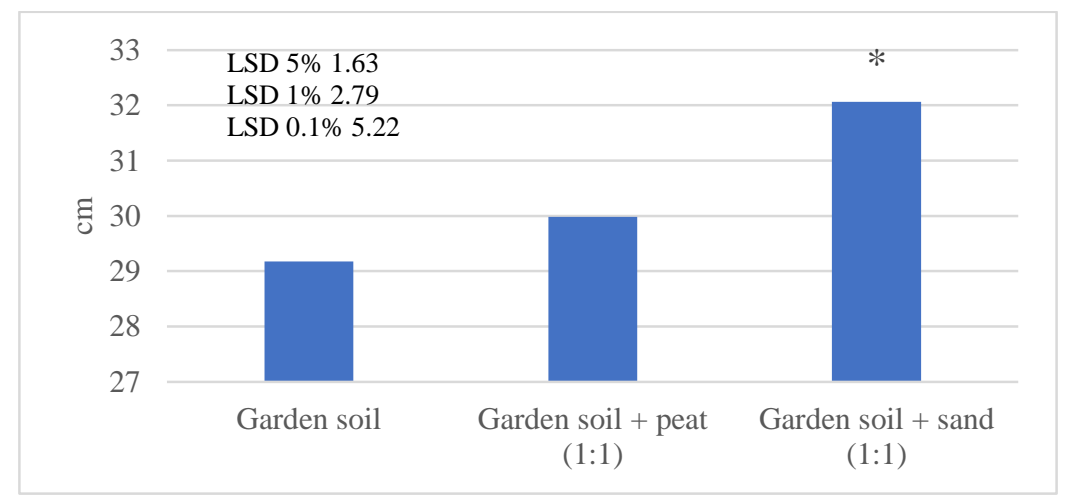

Figure 6. The average length of the floral stem under the influence of the culture substrate

By analysing Figure 6, we can see that the highest average height of the flower stem was recorded in the garden soil + sand (1:1) (average height: 32.06 $\mathrm{cm})$, followed by the garden soil + peat substrate $(29.98 \mathrm{~cm})$. In the case of the mixture of garden soil and sand, there was an increase in the average plant height of $1.65 \mathrm{~cm}$, which is a statistically significant positive difference.

The length of the stem flower for the 15 experimental variants was between $22.70 \mathrm{~cm}$ and 36.65. In Figure 7, which shows the combined influence of the culture substrate and the variety regarding the height of the flowering of the floral stem of hyacinths, it can be noticed that the highest plants with an average height of $35.65 \mathrm{~cm}$ were recorded for the 'City of Haarlem' in the combination with garden soil + sand, followed by the combination of 'Blue Jacket' and garden soil. In this case, the average plant height was $35.20 \mathrm{~cm}$. In both experimental variants, the difference compared to the control of the experiment (mean height, with a value of $30.41 \mathrm{~cm}$ ) was very significantly positive. 


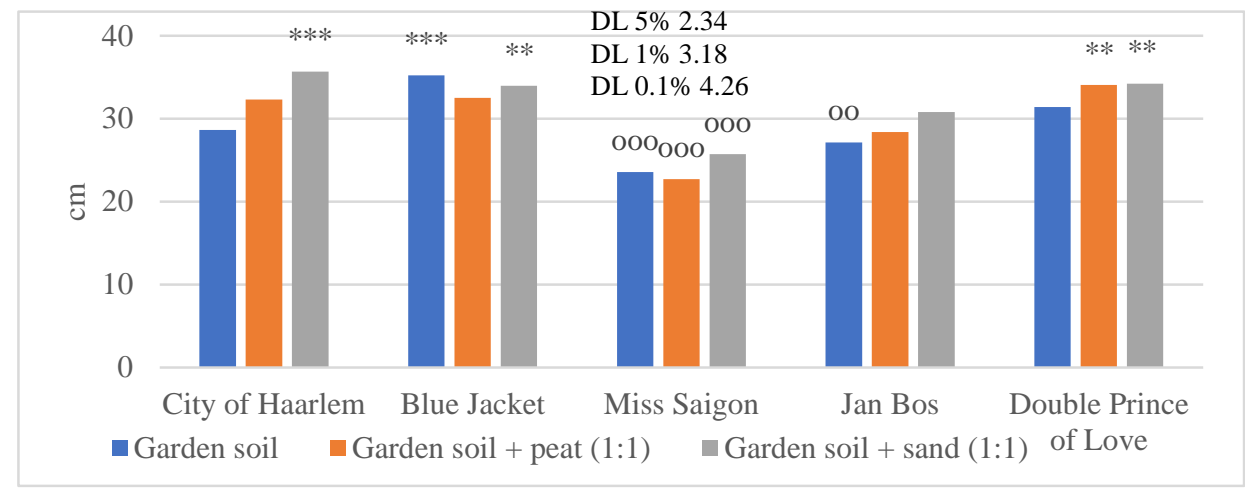

Figure 7. Length of stem flower under the combined influence of the substrate and the variety $(\mathrm{cm})$

The results are in accordance with the results achieved by Toma et al. [16], who obtained a length of stem flower between $23.2 \mathrm{~cm}$ for the 'Peter Stuyvesant' cultivar and $33.4 \mathrm{~cm}$ for the 'Delft Blue' forced in pots placed at a forced temperature of $8-9{ }^{\circ} \mathrm{C}$. On the other hand, the plants with the lowest average height were those from the 'Miss Saigon' variety, which recorded minimum values of this parameter in all three substrate types; the height of the plants decreased with $20 \%$ compared to the average of the experience.

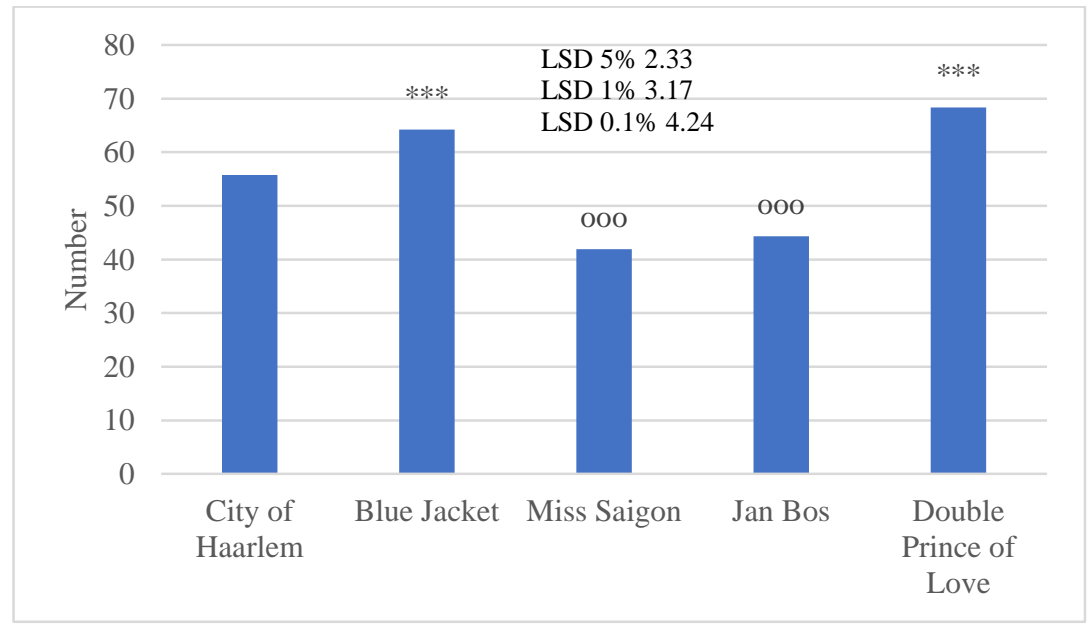

Figure 8. Number of flowers in inflorescence under the influence of variety

The varieties 'Blue Jacket' and 'Double Prince of Love' showed the largest number of inflorescence flowers with 64.25 and 68.35 flowers, respectively, and 
with $17.0 \%$ and $24.5 \%$ more, respectively, than the average of the experience. In both varieties, differences compared to the control, the average of the experience, were very significantly positive (Fig. 8). Concerning the number of flowers in inflorescence, the results are superior to those obtained by Toma et al. in 2012 [16].

The 'Miss Saigon' and 'Jan Bos' varieties had a smaller number of flowers - on average: 41.93 for the 'Miss Saigon' variety and 44.30 for the 'Jan Bos' variety -, the differences of 12.98 and 10.61 flowers/inflorescence compared to the average being very significantly negative results.

From the analysis shown in Figure 9, it can be noticed that the best results were recorded in the case of garden soil + sand (61.36 flowers/inflorescence), followed by garden soil + peat (55.18 flowers/inflorescence) and garden soil (48.20 flowers/inflorescence). Compared to the average experience of 54.91 flowers/inflorescence, the substrate composed of garden soil + sand (1:1) recorded a plus of 6.45 flowers/inflorescence, which is distinctly significant in statistical terms. On the other hand, in the case of culture substrate composed only of garden soil, inflorescences had $12.2 \%$ less flowers than the control of the experiment, the difference of 6.71 flowers/inflorescence being significantly negative. Results are in accordance with those obtained by Sabo et al. [17].

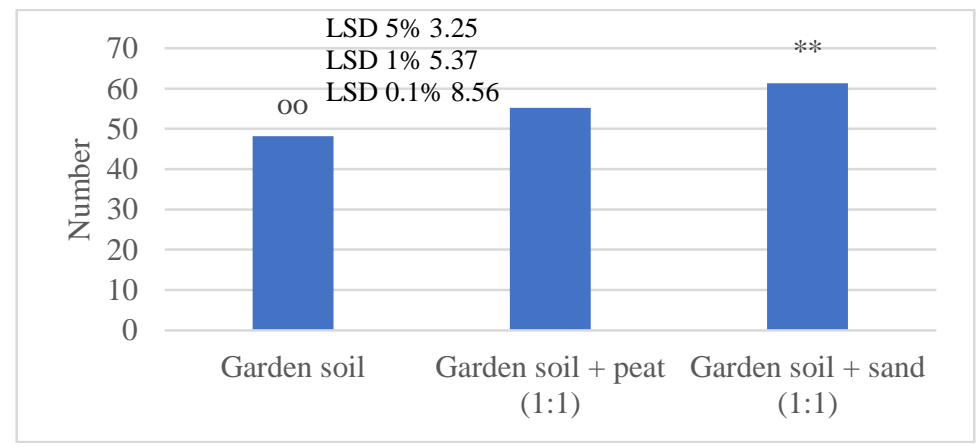

Figure 9. The number of flowers in inflorescences under the influence of the culture substrate

In the case of the below-mentioned variants (Fig. 10), there were positive, highly significant differences, compared to the control, the average of the experience having a value of 54.91 flowers/inflorescence.

The lowest number of flowers in inflorescence was observed with 'Miss Saigon', cultivated in all three substrates, as well as with 'Jan Bos', cultivated in garden soil and garden soil + peat. In the case of these variants, the average number of flowers in the inflorescences ranged from 34.75 to 47.55 , all cases showing highly significant negative differences from the average of the experience. 


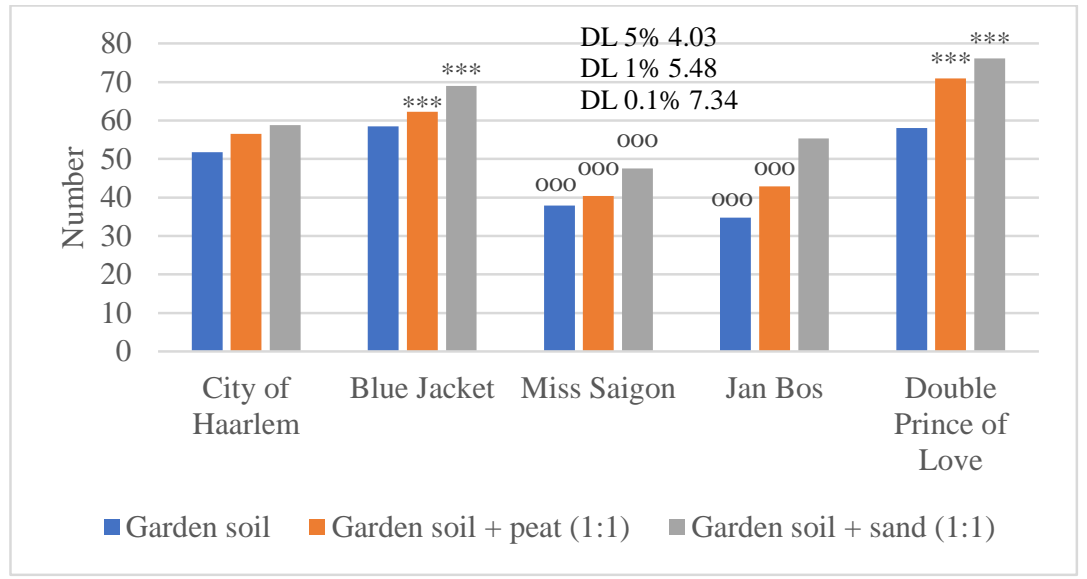

Figure 10. Number of flowers/inflorescences under the combined influence of substrate and variety

The 'Jan Bos' was the earliest blooming variety because it flourished in 12.44 days after being introduced into the greenhouse, while the 'Double Prince of Love' variety needed not less than 17.46 days of heat, making it the slowest in terms of flowering (Fig. 11).

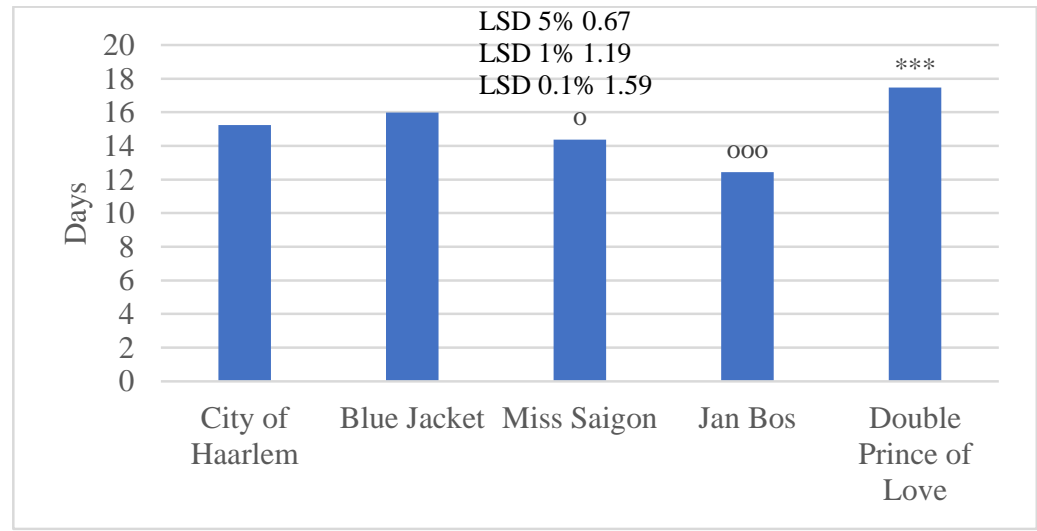

Figure 11. Precocity of flowering under the influence of the variety (days)

The analysis illustrated in Fig. 11 shows that 'Jan Bos' needs the fewest days to flourish from the time of introduction into the greenhouse, averaging 12.44 days, $17.6 \%$ less than the average experience of 15.10 days, thus recording a difference of 2.65 days, which is significantly negative. With a significantly 
negative difference from the control, the 'Miss Saigon' variety, which took an average of 14.37 days to flourish, was $4.8 \%$ less than the average.

The 'Double Prince of Love' needed the longest period to flowering (17.46 days), with 2.37 days longer than the average experience; so, the difference was very significantly positive.

Even if the variety used had a strong influence on bloom precocity, this is not valid for the substrate used as well, the data presented in Fig. 12 showing that only the substrate made up of garden + sand soil led to a small delay in flowering.

Thus, it can be noticed that only the substrate made up of garden soil + sand had a significant influence on the analysed character, a variant in which blooming occurred 1.18 days later than the average of the experience.

Using the other two substrates, garden soil and garden soil + peat, the plants flourished in about 14.5 days from the date of introduction into the greenhouse.

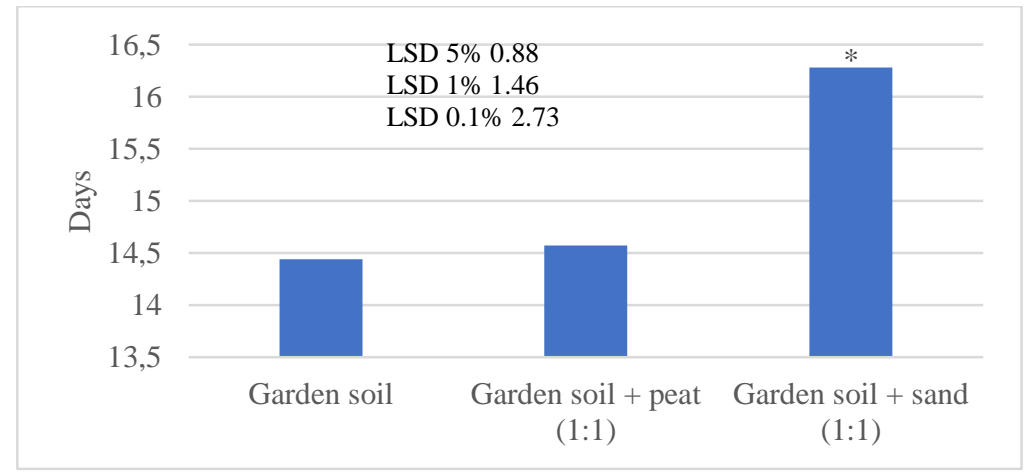

Figure 12. Precocity of flowering under the influence of the variety (days)

Analysing Fig. 13, we can observe that the number of days required for the plants to flourish from the date of introduction into the greenhouse was between 11.12 days for 'Jan Bos' cultivated in the garden and 18.45 days for the 'Double Prince of Love' cultivated in a mixture of garden soil + sand.

Determinations carried out for bloom precocity demonstrate that the variant that can be characterized as the earliest in terms of blooming is the combination of the 'Jan Bos' variety and the garden soil substrate. In this case, the plants bloomed - on average 11.12 days - by $26.36 \%$ fewer days than the average of the experience. The difference between this variant and the average of the experience is 3.98 days, which is very significantly negative (Fig. 13). Also, the 'Jan Bos' variety cultivated in garden soil + peat (1:1) shows a significantly negative difference, in which case the flowering took place in approximately 12 days, almost 3 days earlier than the calculated average. 


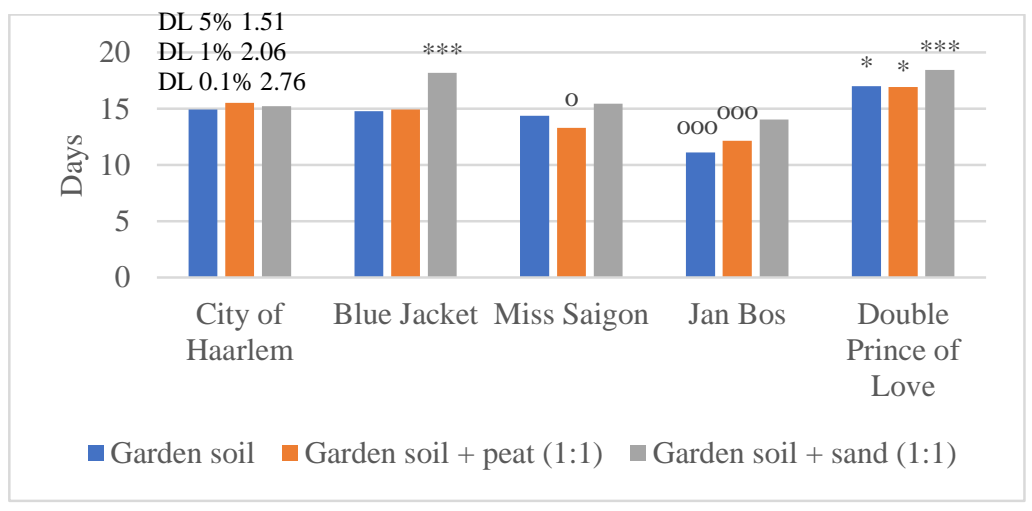

Figure 13. Precocity of flowering under the combined influence of culture substrate and variety (days)

On the other hand, we can mention the following experimental variants: 'Blue Jacket' and 'Double Prince of Love', grown in garden soil + sand. In both variants, blooming took place after 18 days kept in forced culture.

The flowering period of the five studied varieties of hyacinth is presented in Fig. 14. The results of this work show that the variety had an influence on this character. Sabo et al. [17] also found similar results with hyacinths.

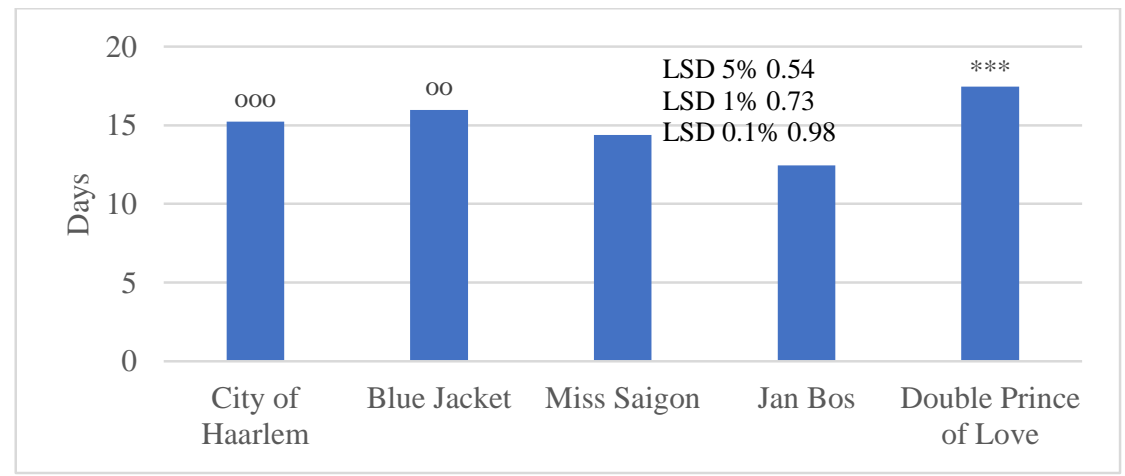

Figure 14. Flowers' flowering period under the influence of variety (days).

Thus, the flowering period varied between 12.44 days for the 'Jan Bos' variety and 17.46 days for the 'Double Prince of Love' variety, while the other varieties yielded values close to $14-15$ days.

For 'City of Haarlem', the difference from the average of experience of 9.94 days was 1.87 days, which is very significantly negative. For the 'Double Prince of Love' variety, the difference from the average was 2.17 days, which is a significantly positive difference. 
Also, with long flowering period are the varieties 'Miss Saigon' and 'Jan Bos', which flourished for more than 10 days, but the differences from the control are statistically insignificant.

As can be seen in Fig. 15, the substrate of culture had a great influence on the flowers' flowering period of the hyacinths.

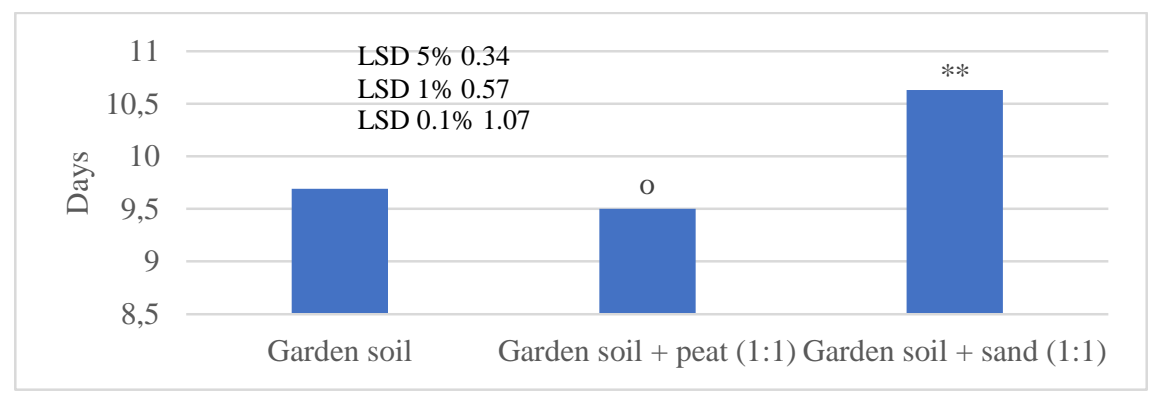

Figure 15. The flowers' flowering period under substrate influence (days)

Thus, the longest flowering period (10.63 days) was registered for plants grown in a mixture of garden soil + sand $-6.9 \%$ longer than the average of experience. The difference from the control of the experiment was in this case 0.69 days, which is distinctly positive.

When cultivating plants in a substrate consisting of garden soil + peat, the flowering period is only 9.50 days, $4.4 \%$ days less than the average of the experience, the difference of 0.44 days being significantly negative.

The combined influence of the cultivar substrate and the variety used on the flowering period of the hyacinths shows that the 'Double Prince of Love' variety was the best one. Cultivating this variety in a substrate made up of garden soil + peat and garden soil + sand, the duration of the flowering period exceeds 12 or even 13 days. Remarkable results were also obtained in the 'Jan Bos' variety, in plants that were planted in the garden soil + sand, in which case the flowers had a blomming period of about 12 days. From a statistical point of view, the differences from the average experiences of 9.94 days were significantly positive in all the variants presented above (Fig. 16).

The experimental variants with a short flowering period are represented by the 'City of Haarlem' variety, cultivated both in garden soil + peat and garden soil + sand. Plants from these variants recorded blooming periods of 7.14 days and 7.66 days, with differences of 2.80 and 2.28 days compared to the average of experience - both variants were statistically significantly negative. 


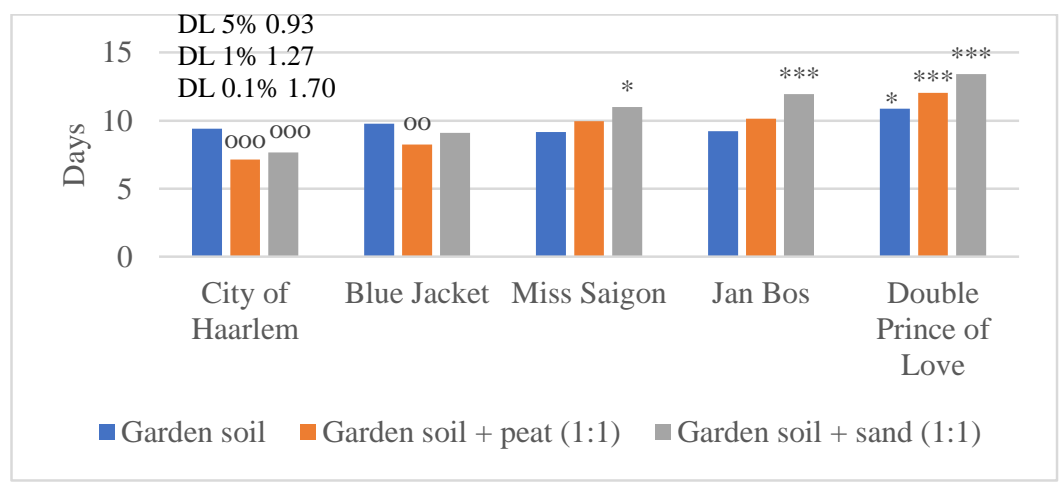

Figure 16. The flowering period of hyacinth under the combined influence of the culture substrate and the variety (days)

\section{Conclusions}

Regarding the substrate of culture formed by garden soil + sand, there were very good results regarding the height of the plants, the number of flowers in the inflorescences, and the flowers' blooming period, but less favourable results were obtained in terms of flowering precocity. Satisfactory results were also obtained for the substrate culture consisting of garden + peat (1: 1) with insignificant differences regarding the studied morpho-decorative characteristics.

Garden soil yielded less favourable results in the flowering period, the height of the floral stem, and the number of flowers in the inflorescence.

The study also demonstrated that the varieties 'Double Prince of Love' and 'Blue Jacket' achieved the best results in the same substrate and can be promoted on the Romanian market as pot plants for forced culture.

\section{References}

[1] Toma, F. (2009), Specii utilizate ca plante în ghivece pentru decorul interioarelor. Vol. 3. Bucharest: INVEL.

[2] *** https://www.steenvoorden.nl/bestanden/Forcing_Guide_Hyacint_English.pdf.

[3] Janse, J. A. (1966), In Geuren en Kleuren, een Geschiedenis van de Hollandse Bolgewassen. Utrecht: Oosthoeks' uitgeversmaatschappij.

[4] De Hertogh, A. (1974), Principles for forcing tulips, hyacinths, daffodils, Easter lilies and Dutch irises. Scientia Horticulturae 2(1974), 313-355. Amsterdam: Elsevier Scientific Publishing Company.

[5] Şelaru, Elena (2002), Cultures for cut flowers. Bucharest: Ceres. 258-266.

[6] Băla, Maria (2012), Floricultură generală și specială. Timișoara: Editura Partoș. 247-249.

[7] Buzatu, Mihaela (2001), Plante floricole cu bulbi rezistente la îngheț. Timișoara: BRUMAR.

[8] Cantor, Maria (2016), Floricultură specială. Cluj-Napoca: AcademicPress.

[9] Teresa, M. (2007), Plante de balcon și grădină. Bucharest: ALLFA. 
[10] $* * *$ https://www.suttons.co.uk/Gardening/Flower-Bulbs/All-Bulbs/Hyacinth-Bulbs-Cityof-Haarlem_290554.htm.

[11] *** https://www.highcountrygardens.com/flower-bulbs/hyacinth-flower-bulbs/hyacinthblue-jacket.

[12] *** https://www.highcountrygardens.com/flower-bulbs/hyacinth-flower-bulbs/hyacinthmiss-saigon.

[13] *** https://www.bluestoneperennials.com/BHYJB.html.

[14] *** https://gardenseedsmarket.com/hyacinthus-double-prince-of-love-hyacinth-doubleprince-of-love-3-bulbs.html.

[15] Ardelean, M., Sestraș, R., Cordea, Mirela (2007), Tehnică experimentală horticolă. ClujNapoca: AcademicPress.

[16] Toma, F., Petra, Sorina, Zamfir-Vasca, Diana, Tanase, Oana (2012), Research on the behavior of some hyacinth varieties in different types of forcing for blooming in out of season. Scientific Papers, Series B, Horticulture LVI, 197-202.

[17] Roxana Alexandra, Sabo, Buta, Erzsébet, Moldovan, Ioana, Cantor, Maria (2018), Research regarding the influence of the cultivar and culture substrate on hyacinths forcing culture. Current Trends in Natural Sciences 7(13), 176-186. 